\title{
A crise das crises: impactos económicos da Covid-19 no curto e no longo prazo
}

The crisis of crises: economic impacts of Covid-19 in the short and long term

Laura Carvalho* Universidade de São Paulo

lcarvalho@usp.br doi: $x \times x x x x x x x x$

\begin{tabular}{|c|c|c|}
\hline Recebido / Received & Aceite / Accepted & Publicado / Published \\
30.07 .2020 & 1.09 .2020 & 1.06 .2021 \\
\hline
\end{tabular}

Como citar este capítulo / How to quote this chapter:

Carvalho, L. (2021). "A crise das crises: impactos econômicos da Covid-19 no curto e no longo prazo". In Reis, B., Um mundo de incertezas; as leituras possíveis de um tempo pandémico (pp. 131-148). Lisboa: NIP-C@M \& UAL, disponível em $\underline{x x x x x x x x}$. DOI $x x x x x x x$.

* Professora Associada, Departamento de Economia, Universidade de São Paulo 


\section{Introdução}

A crise pandêmica da Covid-19, pelos dados disponíveis, deve tornar-se a mais profunda da história económica mundial. Distingue-se de outras crises globais como a de 1929 ou a de 2008, não só pela profundidade, mas também pela grave dimensão sanitária e social que está na sua origem. Distinguese também de outras pandemias por se dar num mundo muito mais integrado. Talvez por isso, a pandemia tenha chacoalhado, como em poucas ocasiões anteriores, a perceção da sociedade sobre o funcionamento do sistema, o custo das desigualdades e os diferentes papéis do Estado.

É verdade que a crise financeira global de 2008-2009 já tinha trazido questionamentos profundos ao modo de funcionamento do sistema capitalista desde as décadas de 1980 e 1990, bem como à forma de atuação dos governos e ao pensamento económico que lhe dá sustentação. A centralidade da desigualdade para a dinâmica macroeconómica, os altos custos da desregulação financeira, o papel dos Bancos Centrais e dos gastos públicos para a estabilização dos níveis de emprego foram alguns dos temas que voltaram a receber a atenção dos economistas e dos executores de políticas nos últimos 12 anos. As dificuldades dos governos socialdemocratas ao redor do mundo, de entregar resultados materiais para uma massa de trabalhadores cada vez mais vulnerável na era da globalização, também ganhava um papel central no debate sobre a emergência de novas plataformas de extrema-direita em diferentes países. 
Em pesquisa $^{1}$ realizada com um painel de renomados economistas europeus, a Initiative on Global Markets (IGM) da Universidade de Chicago encontrou que apenas $2 \%$ dos participantes discordam da afirmação de que "o aumento da desigualdade está prejudicando a saúde da democracia liberal", e apenas 7\% rejeitam a ideia de que "políticas e gastos redistributivos provavelmente limitariam o crescimento do populismo".

Cabe ressaltar, portanto, que foi sobre esse terreno de transformação lenta no campo do pensamento e da política que chegou a pandemia ${ }^{2}$. É possível que o amadurecimento dessas ideias ao longo de mais de uma década tenha desempenhado um papel fundamental em 2020, tanto para a resposta dos governos diante da necessidade de destinar recursos e esforços substantivos para enfrentar a crise, quanto para a atenção conferida pela sociedade às lacunas e injustiças que dificultavam seu combate. A rapidez e a magnitude dessas reações levaram muitos analistas a projetarem o fim do neoliberalismo ou até do próprio capitalismo como conhecemos. Ao fim da tragédia, nasceria um mundo mais justo e sustentável.

O problema é que a pandemia não apenas ilumina desigualdades, também as amplia. Num estudo publicado

1 Chicago Booth, 20 de setembro de 2019, "Inequality, Populism, and Redistribution". 2 Para uma análise mais aprofundada dessas transformações, ver Curto-circuito: $o$ vírus e a volta do Estado (2020) de Laura Carvalho. 
em maio de 2020, pesquisadores do $\mathrm{FMI}$ analisaram ${ }^{3}$ dados de 175 países em cinco graves epidemias - Sars (2003), H1N1 (2009), Mers (2012), Ebola (2014), Zika (2016) - e estimaram um aumento de quase $1,5 \%$ na desigualdade de renda nos cinco anos seguintes. Além da perda de renda e trabalho, que atinge desproporcionalmente os trabalhadores autónomos e informais, bem como os trabalhadores menos escolarizados, que constituem a maioria dos empregados nos setores de serviços, comércio e construção - os mais afetados pela crise -, os mais vulneráveis estão mais sujeitos à própria contaminação pelo vírus e ao óbito. Desigualdades no acesso à moradia, transporte, saneamento básico e saúde são alguns dos elementos por trás desses números. Evidências sugerem ainda que o próprio desenvolvimento das doenças crónicas associadas aos quadros mais graves da doença, como diabetes, hipertensão e problemas cardiovasculares, são desigualmente distribuídos na população, contribuindo para aumentar o número de óbitos entre os mais pobres.

Além disso, a pandemia também deve atuar como vetor de concentração de riqueza pela grande dificuldade de sobrevivência dos pequenos negócios. Empresas pequenas irão à falência diante da dificuldade de continuar a arcar com os seus compromissos ou serão adquiridas por empresas maiores, o que facilitará a formação de oligopólios e prejudicará os consumidores. 
entre países. Uma pesquisa publicada na revista The Lancet (Murray et. al., 2007), sobre a gripe espanhola de 1918, sugere que naquela ocasião as taxas de mortalidade foram até trinta vezes maiores nas regiões mais pobres do mundo. Outro estudo de 2013 (Simonsen et. al., 2013) indica que com a pandemia do H1N1 em 2009 não foi muito diferente: de acordo com as estimativas, a mortalidade foi vinte vezes maior em países da América do Sul do que na Europa. Ou seja, os países que mais precisariam destinar esforços para combater a crise são aqueles menos dotados de recursos para enfrentá-la. E para piorar, como já é habitual em contextos de fortes incertezas globais, essa capacidade de financiamento ficou ainda mais restrita na pandemia pela forte saída de capitais das economias periféricas para os países centrais e seus ativos financeiros mais seguros.

Como esperar que o mundo herdado da pandemia seja melhor do que o que já tínhamos? As desigualdades ampliadas não limitarão as possibilidades de transformação social? Os patamares mais elevados de dívida pública não servirão novamente como oportunidade, tal como nos anos que sucederam a crise de 2008-2009, para a implementação de políticas de austeridade com alto custo social?

Por mais que essas ideias estejam em disputa, o mundo póspandemia não é independente das respostas dadas durante a própria pandemia. Após realizar um diagnóstico da crise económica e social causada pela Covid-19 e dos diferentes tipos de medida requeridos, e tomados para enfrentá-la, vamos 
examinar os problemas estruturais do atual sistema económico que a pandemia pode contribuir para exacerbar.

\section{As duas fases da crise pandémica}

Ao contrário das crises de 1929 e de 2008, em que a economia real foi contagiada por um colapso originado no sistema financeiro, a quebra dos elos macroeconómicos entre produtores e consumidores deu-se em 2020 pelo contágio da economia por um vírus. Essa diferença é crucial. A experiência constituída a partir de crises anteriores é de que, é possível reativar a dinâmica macroeconómica em meio à recessão, por meio de estímulos governamentais à demanda, pela expansão dos gastos públicos e a expansão monetária. $O$ problema é que as políticas anticíclicas convencionais não funcionam plenamente durante uma pandemia em que, de um lado, setores inteiros devem permanecer fechados para evitar a contaminação e, de outro, não é nem sequer desejável que os consumidores retomem as suas atividades habituais de gasto, expondo-se ao risco de contágio. $O$ caráter dual da crise pandémica, que paralisa tanto o lado da oferta quanto o lado da demanda, e o fato de sua resolução depender de medidas que ultrapassam a esfera económica, a tornam singular na história económica.

Para entender tais efeitos é útil dividir a dimensão econóômica da crise em duas fases. Na primeira, em que o contágio pelo vírus ainda não foi controlado, a recessão é inevitável pelas razões já elencadas e as medidas económicas necessárias podem ser divididas em quatro eixos principais. Primeiro, é 
fundamental a destinação prioritária de recursos para a área da saúde e o combate à origem da crise, ou seja, à pandemia. Segundo a expansão de transferências de renda a famílias deve ser rápida e em magnitude suficiente para garantir, sobretudo em países com maior grau de informalidade e desigualdade no mercado de trabalho, a compatibilidade entre os objetivos, nem sempre conciliáveis, de minimizar o risco de contágio pelo vírus e manter níveis mínimos de subsistência. Terceiro, as políticas governamentais voltadas à preservação de vínculos empregatícios por meio do compartilhamento com empregadores dos custos com a folha salarial, são cruciais para atenuar a própria recessão e para evitar uma perda permanente de renda. Por fim, um quarto eixo de medidas deve voltar-se à sobrevivência das empresas, sobretudo os pequenos negócios - menos capazes de absorver o choque e manter o pagamento de aluguéis, salários e outras contas - por meio de garantias e subsídios a operações de crédito, e outras formas de socorro.

Diferentes países e regiões responderam em maior ou menor grau em cada um desses eixos. De acordo com o Monitor Fiscal de respostas à Covid-19 do Fundo Monetário Internacional $(\mathrm{FMI})^{4}$, as dez economias classificadas como avançadas ${ }^{5}$ do $\mathrm{G} 20$ gastaram, em média, $6,6 \%$ do PIB a mais com o enfrentar da pandemia, incluindo o diferimento de receitas com impostos. A média de gastos com saúde nesses países foi de $0,5 \%$ do $\mathrm{PIB}$, com a maior parte dessas despesas sendo destinada para programas de transferência de renda e preservação de 4 International Monetary Fund, abril de 2021, "Fiscal Monitor Database of Country Fiscal Measures in Response to the COVID-19 Pandemic".

5 Austrália, Canadá, França, Alemanha, Itália, Japão, Coreia, Espanha, Reino Unido, Estados Unidos. 
empregos. Dentro desse grupo, enquanto países como Estados Unidos e Japão gastaram $12,3 \%$ e $11,3 \%$ do PIB com essas medidas, respetivamente, França, Itália e Espanha dispenderam entre $2,7 \%$ e 3,5\% do PIB nessas áreas. No que tange aos gastos adicionais com saúde, os EUA dispenderam 1,5\% do PIB, ante 0,05\% do PIB nos países da União Europeia. Essa diferença pode decorrer da própria falta de um sistema público universal e gratuito de saúde nos EUA - uma lacuna que certamente exigiu maiores despesas extras em meio à pandemia.

Quando passamos às operações de compra de ativos, crédito, garantias para empréstimos e outras formas de injeção de liquidez no sistema, os países europeus responderam de forma mais substantiva. O mesmo conjunto de dez economias destinou $15,1 \%$ do PIB a essas medidas, sendo 2,6\% do PIB nos EUA e 34\% do PIB na Itália, por exemplo. Cabe ressaltar que $11,2 \%$ do PIB foram usados por esse grupo de países para conceder garantias de modo a facilitar as operações de crédito para empresas em dificuldade.

Nas dez economias do G20 classificadas como em desenvolvimento ${ }^{6}$, os gastos adicionais e os adiamentos de imposto voltados ao enfrentamento da crise totalizaram apenas $2,8 \%$ do PIB, dos quais os mesmos $0,5 \%$ do PIB foram destinados para a área da saúde. Ou seja, esse conjunto de países gastou cerca de três vezes menos nos demais eixos de resposta à crise em relação ao tamanho de suas economias e dez vezes menos,

6 Argentina, Brasil, China, India, Indonésia, México, Rússia, Arábia Saudita, África do Sul e Turquia. 
se considerarmos o valor absoluto em dólares, do que os dez países ricos analisados anteriormente. Quando passamos às medidas de crédito e injeção de liquidez, as dez economias em desenvolvimento destinaram $3 \%$ do $\mathrm{PIB}$, dos quais $2,7 \%$ do PIB foi para garantias em operações de crédito.

Esses números ilustram como os países distribuíram de forma distinta suas prioridades nessa primeira fase da crise, mas também como uma resposta mais substantiva foi limitada pelo menor espaço fiscal em países periféricos. Em maio de 2020, os países da América Latina já tinham obtido, em seu conjunto, mais de 1 trilhão de dólares em empréstimos do FMI para enfrentarem a crise, para além dos pacotes adicionais obtidos junto ao Banco Mundial (entre US\$ 7 e 10 bilhões) e ao Banco Interamericano de Desenvolvimento (US\$ 3,2 bilhões) ${ }^{7}$. Tais programas certamente contribuíram para atenuar as limitações de recursos nesses países em meio à pandemia, mas não se mostraram suficientes para impedir que a região se transformasse num dos epicentros globais de contágio e óbito por Covid-19 e nem que tivesse uma contração de 9,3\% do PIB projetada pelo FMI para 2020 (ante queda de $4,9 \%$ projetada para a economia global).

No entanto, entre os países da região, Peru, Chile e Brasil gastaram relativamente mais enfrentando a crise e mesmo assim foram os três países com o maior número de mortos por 100 mil habitantes da região (38,2; 37,7 e 35,3 óbitos por 100 mil habitantes, respectivamente). Já o Uruguai registrou apenas 0,9

7 OECD, 11 de novembro de 2020, "COVID-19 in Latin America and the Caribbean: An overview of government responses to the crisis". 
óbitos por 100 mil habitantes mesmo tendo gastado menos de $2 \%$ do PIB. Para além de diferenças na efetividade das medidas quarentenárias impostas, os níveis distintos de desigualdade estrutural podem contribuir para explicar essas disparidades na região e ao redor do mundo. A desigualdade de renda medida pelo índice de Gini, que varia entre 0 e 100 (onde 100 representa o caso em que uma única pessoa concentra toda a renda), é de 45,9 no Uruguai ante 55,6 no Brasil, 50,3 no Peru e 47,3 no Chile, por exemplo.

Por outras palavras, para além do maior ou menor sucesso em aplicar as medidas sanitárias adequadas, os efeitos da pandemia distinguem-se pela capacidade de resposta dos países no nível da política económica, incluindo recursos destinados à saúde, à preservação de empregos e renda, e ao apoio a empresas em dificuldade. As diferenças nessa esfera não aparecem somente nas diferentes prioridades conferidas, por exemplo, a salvar famílias e/ou empresas, mas também na capacidade de financiar as medidas necessárias e nos elementos estruturais que podem agravar a crise, como desigualdades de renda ou no acesso à saúde.

Em linhas gerais, o fato de ser uma crise singular e que exigiu respostas distintas daquelas experimentadas em recessões anteriores, não quer dizer que elementos estruturais do sistema económico global não a tenham agravado e não sirvam para entender melhor a sua dinâmica em cada país. A dificuldade maior de enfrentá-la passa por várias das tendências observadas 
desde os anos 1980 e 1990 no modo de funcionamento desse sistema. Tendências essas que já vinham levantando questionamentos crescentes ao atual modelo no pensamento económico e na esfera da política desde a crise financeira global de 2008-2009.

Passando agora à segunda fase da crise, evidências ao redor do mundo sugerem que tentativas prematuras de reabertura das economias ou mesmo a adoção de medidas restritivas frouxas, não são suficientes para reativar a dinâmica macroeconómica. Projeções do banco central sueco - país que não chegou a fechar a sua economia - sugerem uma queda entre 7 e $10 \%$ do PIB em 2020 naquele país, ou seja, uma recessão da mesma ordem que a projetada para a Alemanha, por exemplo. Os restaurantes dos primeiros estados norte-americanos a reabrirem suas economias em meio à pandemia não conseguiram recuperar nem $20 \%$ da frequência observada antes da crise. Por isso, a segunda fase da crise, que traz de volta a eficácia dos estímulos macroeconómicos fiscais e monetários como motores de recuperação só se inicia após o controle do contágio. Ainda assim, o alto grau de incerteza em relação a possíveis novas ondas de contágio e novos fechamentos mantém a postura defensiva de famílias e empresas, dificultando a retomada do consumo, da produção e dos investimentos. Quanto mais inadequada tiver sido a resposta na primeira fase e, portanto, quanto maior tiver sido a perda de empregos, o fechamento de empresas e a absorção de famílias em espirais de pobreza em países com redes menos amplas de proteção social, mais difícil é a recuperação dos níveis de renda 
pré-crise no segundo momento. A elevação das desigualdades causada pela crise pandémica também opera como âncora na fase seguinte, contribuindo para reduzir permanentemente a trajetória de crescimento económico potencial.

Por isso, diferentes governos têm debatido agendas de recuperação económica centradas numa expansão de investimentos públicos ou em outras medidas com alto efeito multiplicador sobre a renda e empregos. Mas como viabilizar, por exemplo, um plano de investimentos públicos em infraestrutura física e social com capacidade de puxar uma retomada inclusiva, se a queda na arrecadação e o aumento dos gastos associados ao enfrentamento da primeira fase da crise deixaram de herança um elevado patamar de endividamento dos governos?

Assim, como nos anos que sucederam a crise de 200809, estamos diante da possibilidade de que o alto nível de dívida pública herdado da recessão sirva para justificar a adoção de uma agenda de austeridade com elevado custo social. Nesse contexto, é crucial traçar uma linha entre os governos endividados na própria moeda e com baixo custo de financiamento e aqueles em que a dívida externa, a falta de autonomia da política monetária e a forte saída de capitais em meio às incertezas globais pode limitar o espaço fiscal para a adoção de um plano de recuperação. No primeiro grupo, pode haver uma austeridade auto-imposta a partir das pressões usuais. No segundo, o ajuste fiscal poderá ser forçado, mais uma vez, por instituições multilaterais e outros credores em meio a 
dificuldades crescentes de financiamento. O resultado líquido desses embates e o caminho seguido pela política económica ao redor do mundo dependerá das implicações da crise para algumas tendências que já operavam antes de sua emergência.

\section{As crises do pós-pandemia}

Em artigo ${ }^{8}$ publicado em abril de 2020, Dani Rodrik projetou que essa crise apenas reafirmará as visões de mundo de cada um, num processo que identificou como um super viés de confirmação. Ou seja, enquanto alguns acreditam que a crise pandémica levará à taxação de grandes fortunas, à renda básica universal e à valorização dos sistemas públicos de saúde, outros a percebem como prova da ineficácia dos governos e da ciência, ou da existência de uma conspiração chinesa contra o Ocidente. Nesse contexto, para Rodrik, essa crise apenas reforçará tendências anteriores, entre as quais a crise do neoliberalismo, a crise da globalização ou a crise da própria democracia.

"O neoliberalismo continuará sua morte lenta", afirmou o autor. A crise financeira global de 2008 já havia provocado ruturas importantes no pensamento económico e nas políticas governamentais - do papel crescente atribuído aos gastos e investimentos públicos na pesquisa económica, à atuação estabilizadora de bancos centrais ao redor do mundo. 0 crescimento das desigualdades nos países ricos desde os anos 1980 foi trazido à tona e incorporado por economistas, ativistas e políticos nas suas agendas.

8 Project Syndicate, 6 de abril de 2020, "Will COVID-19 Remake the World?". 
Se os ensinamentos do pós-2008 forem levados a sério, os planos de consolidação fiscal que, porventura, forem implementados em países com maiores restrições ao aumento da dívida pública, não vão repetir o erro de mirar em uma estabilização rápida da razão dívida-PIB, levarão em conta os impactos multiplicadores e distributivos dos diferentes componentes do gasto, e da tributação. A tributação de quem poupa uma parcela relativamente elevada da renda (o topo da pirâmide), e o gasto em valor correspondente com quem consome quase tudo que ganha (a base da pirâmide), tem efeito multiplicador sobre o PIB sem causar nenhuma deterioração no orçamento público. Planos de recuperação inclusiva e sustentável baseados em propostas de Green New Deal já começaram a ser desenhados. Propostas de reforma tributária progressiva também não faltam. $O$ problema é que ao mesmo tempo que estes temas ganharam um peso maior no debate público, os desafios também são cada vez maiores.

Em particular, a crise também exacerbou transformações no mercado de trabalho. Paraalém daescaladabrutal do desemprego em meio à crise e à crescente automação de tarefas, que por si só já tende a retirar poder de barganha de trabalhadores nas negociações salariais, o crescimento do trabalho remoto pode levar a uma precarização ainda maior das relações de trabalho e abrir espaço para um aumento das jornadas, que se tornam menos monitoráveis. $\mathrm{O}$ trabalho por aplicativo ou plataforma explodiu em meio às medidas quarentenárias, correndo o risco de exacerbar tendências anteriores de uberização e de aumentar 
ainda mais a volatilidade da renda, e a perda de direitos trabalhistas mínimos. No âmbito das desigualdades de género e da economia do cuidado, o cenário é devastador: mulheres foram afetadas pelas demandas de trabalho doméstico e o cuidado com crianças e idosos de forma desproporcional, e por vezes incompatível com sua jornada remunerada de trabalho. Já há inclusive evidências ${ }^{9}$ de que a participação das mulheres no mercado de trabalho após a pandemia será menor, tanto em termos de emprego, quanto de renda.

Os desafios do pós-pandemia vão além, portanto, da implementação de um plano de recuperação inclusiva e sustentável para o retorno aos níveis pré-crise de renda. 0 próprio Estado de bem-estar social e as redes de proteção aos mais vulneráveis deverão ser repensadas a partir das tendências futuras do mercado de trabalho. Nesse contexto, cabe ressaltar que os países que mais sofrerão com a destruição de empregos gerada por essas transformações não serão necessariamente os mesmos em que novos postos de trabalho serão criados. Além disso, aqueles que mais precisariam expandir as suas redes de proteção social são, sem dúvida, os que menos terão capacidade fiscal para fazê-lo. Tais tendências reforçam a importância de se redesenhar os atuais mecanismos de solidariedade fiscal entre os países e o caráter desestabilizador do sistema financeiro internacional.

9 Economic Policy Institute, 15 de abril de 2020, "Women have been hit hard by the coronavirus labor market". 
Esse ponto leva-nos a outra das crises identificadas por Rodrik: a da globalização. É provável que aí os líderes e movimentos nacionalistas-nativistas em expansão nos países ricos passem a utilizar um pretexto adicional para barrar a entrada de pessoas e de mercadorias - o risco de contágio -, o que traria consequências para uma parcela ainda maior da população mundial do que os observados desde o ataque terrorista de 11 de setembro de 2001. Por outro lado, a necessidade de cooperação global para o combate a um problema que, pela sua essência, ultrapassa fronteiras nacionais, fortalece o papel das instituições multilaterais e dos mecanismos de solidariedade entre países. Além do peso conferido às recomendações da Organização Mundial de Saúde, a pandemia tornou cristalina a necessidade de uma atuação mais generosa do Fundo Monetário Internacional para a ajuda a países com restrições de recursos e do próprio Banco Central Europeu no financiamento aos gastos de países da periferia do continente. E mesmo quando analisamos a guerra comercial entre os Estados Unidos e a China, a necessidade de importação de insumos e equipamentos médicos durante a pandemia serviu para trazer à tona a forte relação de interdependência económica entre a "fábrica do mundo" e seu principal mercado consumidor.

Por fim, a continuidade, ou não, da crise democrática global depende da própria capacidade de resposta às crises e desafios já elencados - durante e após a pandemia. No artigo intitulado Did austerity cause brexit? Fetzer (2019) utilizou estimativas de incidência dos cortes no orçamento de dez programas sociais 
realizados a partir de 2010 em todos os distritos do Reino Unido, além de dados individuais que documentam se o eleitor recebe algum benefício social e qual o seu voto (ou intenção de voto) declarado. A conclusão foi de que a redução nos programas sociais aumenta substancialmente a declaração de votos pró-brexit, bem como a concordância com afirmações do tipo "o governo não se importa [comigo]". Diversos artigos ${ }^{10}$ na literatura económica também parecem dar sustentação à hipótese de que distritos ou regiões mais expostas à importação de produtos chineses são mais propensas a apoiar partidos de extrema direita nos EUA e Europa ocidental.

Se diante da crise económica mais profunda da história mundial, a resposta das democracias ocidentais (ou do que sobrou delas) não for capaz de evitar que a perda de empregos e renda atinja mais uma vez de forma desproporcional e duradoura a base e o meio da pirâmide distributiva, não há razões para crer numa reversão da tendência ao fortalecimento de diferentes formas de autoritarismo.

\section{Bibliografia}

Carvalho, L. (2020). Curto-circuito: o vírus e a volta do Estado. São Paulo: Editora Todavia.

Fetzer, T. (2019). Did Austerity Cause Brexit?. American Economic Review, 109 (11), pp. 3849-86.

10 American Economic Association, 10 de outubro de 2020, "Importing Political Polarization? The Electoral Consequences of Rising Trade Exposure". 
Murray, C., Lopez, A., Chin, B., Feehan, D. \& Hill, K. (2007). Estimation of Potential Global Pandemic Influenza Mortality on the Basis of Vital Registry Data from the 1918-20 Pandemic: A Quantitative Analysis. Lancet, 368, pp. 2211-8.

Simonsen, L., Spreeuwenberg, P., Lustig, R, Taylor, R. J., Fleming, D. M., Kroneman, M., Van Kerkhove, M., Mounts, A. \& Paget, W. (2013). Global Mortality Estimates for the 2009 Influenza Pandemic from the GLaMOR Project: A Modeling Study. PLoS Med, 10(11), e1001558. 